\title{
Research on Development and Optimization of Human Resources in Gig Economy JINYANG CAO
}

\author{
Ph.D, Faculty of Social Sciences and Humanities \\ Universiti Teknologi Malaysia \\ Johor Bahru, Malaysia \\ hanwen912@sina.com
}

\begin{abstract}
With the rapid development of modern science and information technology, the "employment-labour" approach has dramatically enriched, and the "gig economy" that relies on Internet technology and platforms has emerged to take advantage of the trend. Human resources present a new form of distribution, driving its technology, work, and concept level to achieve deep integration. This employment method activates the part of the human capital stock and improves the efficiency of enterprise employment with high quality; However, obtaining healthy, orderly, and sustainable development and optimisation of human resources in the gig economy market requires continuous exploration and continuous innovation. Furthermore, the gig economy has the characteristics of uneven geographical age distribution, flexibility, and employee autonomy, which has changed the traditional employment model. Based on the analysis of the conceptual boundary of the gig economy and the theoretical explanation of its development trend, the focus is on the opportunities and advantages, risks and challenges of the current and future development of human resource development under the gig economy, and explore the development and optimisation of human resources in this regard. Strategies to seek a new path for sustainable human resource development in the gig economy environment.
\end{abstract}

\section{Keywords: Gig Economy, Human Resource, Pattern Innovation, Develop and Optimise}

\section{INTRODUCTION}

In today's world, technology and industry are changing at a rapid pace. In particular, the Internet, artificial intelligence, big data and other new technological means are constantly rewriting the way of production and life of human beings. The emergence and development of the odd job economy is creating new value increments by releasing idle resources in society through technological means.

The gig economy has a long history. It originally refers to the economic dimension of workers who do not have a fixed work unit and work content but who get job opportunities and remuneration randomly[1]. Its core value lies in the reconstruction and promotion of the "idle labour value" . However, the skill-based, knowledge-based, and creative gig economy is becoming a new trend of development. With the establishment of the Internet platform, more and more people are beginning to use "excess" skills, time, information, and even assets in exchange for remuneration on the mobile or $\mathrm{PC}$ side. As a result, it has gradually formed part-time jobs in the "Internet age." Thus, the economy is increasingly becoming a vital force in promoting "new employment patterns."

According to the World Development Report 2019 released by the World Bank, the gig economy has gradually occupied the job market share, and the global gig economy has even shown explosive growth in recent years[2]. In particular, the sudden new crown pneumonia epidemic in 2020 has caused a fatal blow to the global macroeconomy and surprised society at the opportunities that the gig economy brings to the world. Not only did it protect the lives of residents during the international blockade, but it also promoted the transaction volume of e-commerce, and to a certain extent, promoted the transformation of the professional values of the new generation of workers. The gig economy reconstructs the employment relationship with innovative models such as online transactions, mobile office, and business cooperation.

Although the gig economy model has a specific theoretical and practical basis, human resources also face 
new risks and challenges in the "Internet + gig economy" and digital technology. This paper explores the opportunities and advantages of the human resources of the gig economy in the Chinese market through a study of the domestic gig economy market. It also proposes solutions for the current human resource allocation of the gig economy through a value chain perspective, in order to build and optimise a dynamic, orderly and sustainable human resource framework for the gig economy.

\section{A VALUABLE EXPLORATION OF THE THEORETICAL BOUNDARY AND CORE OF THE GIG ECONOMY}

\section{1"Gig economy" under the view of tradition and creation}

Regarding the concept of the Gig Economy, American scholar Diana Malkaxi explained in "The Gig Economy: An Engine to Promote Social Change": Replace the traditional nine-to-five work with a short and flexible work style forms include consulting, undertaking agreements, part-time jobs, temporary jobs, freelance, self-employed, sideline jobs, and part-time jobs found through freelance platforms. The traditional "part-time job" refers to the work where the workplace is not unique, the work content is not fixed, and the job opportunities are uncertain. The salary is settled daily or settled according to projects, and the person who undertakes this kind of temporary and project work most are freelancers. The first "Gig workers" with professional concepts originated in Europe and the United States, referring to artists performing and singing. They always linger in various performance venues one after another due to schedule issues, as a result, there is not only volatility in working location and work content but also uncertainty in income. In China, odd jobs are often associated with the concepts such as "casual labour." With the policy orientation of "flexible employment" proposed, the gig economy has also shown a good development trend in China.

The gig economy is a people-oriented organisational model and a way of working ${ }^{[3]}$. In a sense, the gig economy mainly uses the Internet platform to make idle resources socially reused. From the perspective of functional analysis, the gig economy can activate employment potential. It also has the function of revitalising labour resources, making numerous labourers in idle states regain employment opportunities. In the economic field of freelancers with a small workload, effective use of Internet technology quickly matches supply and demand, integrates human resource development channels, and achieves financial model innovation for more efficient use of resources. The "odd-job economy" has become a keynote of selfemployment for aspirants around the world, especially in China, where, thanks to the rapid development of 5G technology and internet platforms, odd-job economy participants accounted for $22.73 \%$ of total employment in 2020, according to the Ministry of Human Resources and Social Security, greatly widening access to employment (Figure 1). At present, the judgment of the gig economy in academia is mainly based on two points: the technical support of the digital economy and the economic distribution paradigm of the traditional gig economy. The author believes that the gig economy is mainly a working model in which the two parties involved in the labour market use an intermediary platform to pay compensation based on project results in the digital economy market. The main research variables of the gig economy are workers, demand-side and intermediary media. With the rapid advancement of 5G technology, digital transformation has become a new trend in human resources empowerment, and the platform of gig economy applications has an unprecedented impact on human resources ${ }^{[4]}$.

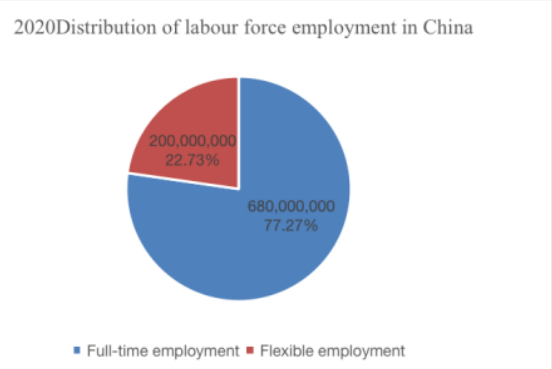

Figure 12020 distribution of labour force employment in China

\subsection{The inherent characteristics and charm of the gig economy}

The reliance on Internet technology is evident. In the International Labor Organization view, the most prominent feature of the gig economy is its reliance on network platforms or Internet technology, and the most attention is about the digital transformation of the network. Because in the matching and optimising labour content and labour objects, or the process of workload distribution and human resource matching, both the labour side and the demand side need to connect through the construction of a network platform to transmit signals that meet the needs of both parties. In addition, there is another way that the platform actively sets the amount of labour. Therefore, the most significant feature of the gig economy is the demand and dependence on the Internet platform or technology.

Increasing tendency of flexibility and autonomy. Some scholars believe that the gig economy relies on Internet platforms, especially mobile applications, to expand labour participation significantly and improve the efficiency of task completion, such as UBER, MeiTuan Takeaway, and Didi Taxi. Indeed, the broadening of the labour force 
involved and the rational use of human resources have directly affected or even subverted the path, efficiency, and results of work instructions from "issuance to execution." Therefore, from the perspective of the gig economy, either workers involved in the implementation of tasks are full-time or part-time, all depending on their different abilities, time and energy, and even differences in cooperation forms, methods, and status. Work efficiency will naturally increase significantly because of flexibility and autonomy.

The short-term nature of project constraints is precise. On the one hand, allocating human resources for groups involved in labour is relatively short. The groups of workers engaged in work are divided into full-time and part-time jobs. Due to insufficient labour security and related constraints on career development, most labour groups can only participate in odd jobs in the form of part-time jobs, generally in terms of project time. Time is the priority. On the other hand, the time limit for the work content agreed by the business requirements will not be too long. Because it takes time and energy to get in touch with core positions and core business, and the agreed work content can be paid, the labour relationship will naturally end. Therefore, its work content also does odd jobs with short-term characteristics.

The external career anticipation is weak. Internal and external careers are the channels for employees to gather value and are also critical to measuring the internal and external values brought by work. However, most of the workers in the gig economy exist in the form of part-time jobs, and most of their work content has the characteristics of solid replaceability, short cycle, relatively simple content, Etc. Moreover, their salary is instead limited the resulting benefits are not enough. Make it enter the core circle of the organisation, and it is challenging to realise the promotion, salary, power development, and other issues concerned by the outside career. Therefore, the lack of chains and low ceilings in foreign careers are another notable feature of the gig economy.

\subsection{The relevance of gig economy, sharing economy, on-demand economy, and digital economy}

Sharing economy is a new field of the Internet and has become an essential source of new and flexible employment. It is mainly a new economic format that improves the efficiency of resource allocation through "sharing the surplus-value." The two main economic methods of the sharing economy are sharing labour and sharing physical objects to obtain benefits. Shared employees in the sharing economy are also called "shared employment," which refers to adjusting specific phased labour shortages or surpluses between different employers and optimising idle labour resources on the premise of respecting employees' wishes and multiparty consensus. It is shared by the industry and deployed to employers with labour demand gaps to achieve a new tripartite win-win cooperative labour model in which the supply side can reduce labour costs, the demand side can solve the "labour shortage," and the waiting employees receive labour compensation. The benefits of sharing physical objects mainly refer to how the contribution borrows items, appliances, Etc., from the other party without transferring ownership, such as sharing power banks, sharing bicycles, Etc. Most researchers confuse the sharing economy with the gig economy, and there are specific differences in the boundaries between the two. It shows that the sharing economy is an economic distribution method, and the gig economy is only the allocation method of human resources. Therefore, considering that the gig economy is conceptually cross with the sharing economy, the two cannot be equal absolutely. The sharing economy and the products or services provided are all related to physical assets. Especially from sharing employees to sharing information, from sharing resources to sharing education, a sudden "new coronavirus pneumonia" (COVID-19) epidemic has caused many industry companies to develop together, and the sharing economy highlights the disintermediation and reintermediation $^{[5]}$. The process of transformation. There are significant differences between the gig economy and the sharing economy. The key lies in achieving optimal matching, achieving zero marginal cost, and solving technical and institutional problems.

The on-demand economy is a subset of the gig economy. The demand side recruits labour according to business needs and organises human resources for project or business needs. Employees can be long-term, accompanying the organisation's life cycle; it can also be short-term, attending the project cycle, or even participate in work daily. It can also be called "production on-demand," "production before consumption," or "order economy." It can reach a higher standard within the scope of resources and technology and respect the instinct of market economy capital to pursue profit. However, one of the main characteristics of the gig economy is that it is shortterm; that is, most workers in the gig economy will be allowed to terminate the labour relationship and receive due to human capital compensation as the business demand is completed. Therefore, although the gig economy and the on-demand economy focus on distributing human resources, the difference between the two lies in the relationship between workers and the demand side; whether there is "short-term" the two is only a cross relationship. The critical difference between the on-demand economy and the gig economy is the immediacy of demand, and the instantaneity depends on the skill level and duration of the gig economy. 
The digital economy accomplishes its mission by relying on informatisation. All economic forms can be included in this category, whether directly or not, to use data to guide resources and promote product development. Mainly take digital knowledge and information as the main production factors, use the network and information technology as the carrier, and use efficient communication technology for economic activities. It plays a vital role in the distribution of social resources and optimising the economic structure. It includes emerging technologies such as big data, cloud computing, the Internet of Things, blockchain, artificial intelligence, and $5 \mathrm{G}$ communications at the technical level. At the application level, "new retail" and "new manufacturing" are all typical representatives. The gig economy is conceptually digital. The intermediary platform of the gig economy uses its advanced digital technology to rely on the dissemination and collection of information to achieve transaction opportunities. Finally, its existence also plays a positive role in promoting and affecting the redistribution of resources. In the future, relying on big data, cloud computing, artificial intelligence, and other technological means will empower high-quality economic development. Various new business forms, including the gig economy, spawned by the digital economy, will also become a unique important growth point for the country's or religion's economy.

\section{THEORETICAL DEFINITION AND SITUATION DESCRIPTION OF THE NEW MODEL OF GIG ECONOMY DEVELOPMENT}

Americans and the Gig Economy 2018 shows that almost a quarter of American adults make money in the gig economy. Thanks to Internet technology, the gig economy has developed rapidly on a global scale. People's enthusiasm for non-traditional employment stems from the great convenience brought about by flexibility, which breaks the time and space constraints of the labour market and encourages more people to participate (Li, Hong, \& Zhang, 2018); at the same time, flexibility Employment also enables companies to respond more quickly to market changes. The gig economy generally refers to an unstructured work arrangement that is different from the traditional one. Internet technology has given the gig economy a new development model. Internet technology more efficiently matches the supply and demand sides so that this type of employment can quickly spread to all aspects of the labour market (Lehdonvirta, Barnard, Graham \& Hjorth, 2014). The supply and demand sides have broader flexibility based on the separation of traditional labour relations, it makes working hours, locations, and remunerations no longer follow uniform and fixed rules (Eichhorst, Hinte, Rinne), \& Tobsch, 2017). Digital supervision reshapes the relationship between organisations and individuals, user rating and reputation systems replace human resource management in employment relationships, and further promote the high degree of autonomy of gig workers and the diversity and complexity of work tasks ( Wood et al., 2019). Therefore, the gig economy can be defined as an online market for temporary workers with an online platform as an intermediary (Manyika et al., 2016). Although the rise of the gig economy relies on the development of the digital economy, technology itself has not changed the market's demand for labour, and the characteristics of flexibility respond to the preference of enterprise cost and risk control.

With the development of the Internet, the gig economy has more suitable soil for growth. The current trend of gig economy development tends to be flexible, high-quality, and efficient, and is generally beneficial to society and serves the public, making human resources shift from social idleness to a balance of social needs. From this point of view, the gig economy is different from the traditional employment model. It mainly has three characteristics: job fragmentation, job flexibility, and remote cooperation. Nowadays, the "gig economy" discussed in academic circles and the industry is different from the "gig economy" of the old age, and it should be called the "new gig economy." Expressly, it can be understood as an economic form driven by digital information technology, where labour and management voluntarily benefit from each other on the Internet and technology platforms and ultimately realise work or economic relations. The value of human capital consists of both explicit and implicit human capital, and ultimately requires the unification of the values of society, business and human capital. The design and selection of human capital value measurement methods should take into account the characteristics of human capital.The author believes that the current development of the gig economy is slightly immature, mainly because the economic model needs to be continuously optimised, and the quality of service needs to be improved. Many issues need to be discussed in terms of standardisation and high quality, such as the temporary employment relationship between employees and organisations, how to protect the rights and interests of both parties, brand culture and organisational communication, high-cost issues caused by frequent employee turnover, Etc. These are topics worthy of joint discussion between academia and industry.

\section{ALLOCATION OPPORTUNITIES AND EFFICIENCY ADVANTAGES OF HUMAN RESOURCE DEVELOPMENT IN THE GIG ECONOMY FIELD}

With the rapid development of new technologies such as the Internet of Things, Cloud Computing, and Big Data, the opportunity for human resource allocation 
lies in relying on the widespread application of Internet technology to directly provide the technical prerequisites for the vigorous development of the gig economy ${ }^{[6]}$. Mainly manifested in: Firstly, the establishment of the Internet platform has broadened the employment and recruitment calibres for labour and management, making it easier for labourers and management to obtain massive amounts of data and opportunities; Secondly, the application of big data provides companies with more accurate employee portraits, It dramatically improves the accuracy of recruit behaviour. It is definitely that the economic form of the gig economy indeed conforms to the development of the times and maximises the social effectiveness of human resources. The author believes that, in general analysis, the coordinated development of the gig economy is sustainable and beneficial to the development of human resources in society. The main advantages reflect in:

\subsection{Effectively increase additional legal income.}

Such as labour input-based economic forms: Uber, DiDi, Etc.; another example of asset input: Airbnb leasing, Etc., most of the gig economy practitioners in these industries not base on a subsistence income, but idle assets are. The gain is from exchanging work or assets, which means that the revenue from the odd labour activities does not make a living on their additional income boost. In this scenario, the value of the firm's human capital is determined, and then the formula is calculated as:

$$
V=\sum_{t=1}^{n} \frac{w_{t}}{(1+r)^{t}} \frac{\sum_{t=0}^{m-1}(m-t) \frac{R F_{t}}{R E_{t}}}{\frac{m(m+1)}{2}}
$$

Where: V denotes the value of the firm's human capital; $\mathrm{w}[, \mathrm{t}]$ is the wage compensation in year $\mathrm{t} ; \mathrm{n}$ is the number of years of calculation; $r$ is the discount rate; $\mathrm{RF}[\mathrm{t}]$ is the firm's return on assets in year $\mathrm{t}$ and $\mathrm{RE}[, \mathrm{t}]$ is the $\mathrm{t}$ the industry-wide average rate of return on assets in year $\mathrm{t}$.

From the perspective of the value of human capital: income is an important proof of the value of human capital (Equation 1). Therefore, as the income of practitioners increases, it is also direct evidence of the increase in the value of human capital through their participation in odd jobs economic activities.

\subsection{The flexibility of interval regulation is rich.}

Some part-time workers, such as China's Meituan takeaways or designated drivers, may have multiple jobs. Some have their own main business during the day, while others make a living by doing numerous odd jobs. Even so, someone can also squeeze out time to engage in part of odd jobs, requiring efficient overall planning of time. The main reason is that part-time work has a wide range of time requirements. It only needs to complete the specified tasks with quality within the specified time. As for the time, who will "prescribe" the time, and the degree of freedom is relatively large. Human capital pricing is the effective measurement of the value of human capital. Based on the estimation of the implicit value interval of individual human capital, we seek to construct a model and innovative method for measuring the individual value of human capital by converting explicit and implicit human capital values.

\subsection{Broaden the development of internal career.}

Although there are also some workers, the primary purpose of choosing part-time jobs is not to get remuneration as the first task. It may just be overcapacity or enthusiasm-for example, some designers, writers, programmers, Etc. In addition to the central business will also take over some "private work" and use the project as the node for settlement. As far as it is concerned, such odd jobs are primarily due to surplus capacity or horizontal projects generated by the main business. For it, engaging in odd jobs is mostly about perfecting the development of one's career. In this scenario, the expectation of the value of the firm's human capital is then calculated as:

$$
V=\sum_{t=1}^{n} \frac{\sum_{t=1}^{m} R_{i} P\left(R_{i}\right)}{(1+r)^{t}}
$$

Where: V denotes the value of human capital; R[, i] denotes the benefit that the employee can bring to the organisation when in position $i$ i.e. the value created for the organisation; $\mathrm{P}(\mathrm{R}[$, i] $)$ is the probability of the employee acquiring position $\mathrm{i}$; $\mathrm{m}$ is the number of positions that the employee may hold during the expected number of years of service in the enterprise; and $n$ is the expected number of years of service in the enterprise for the employee.

Since odd-job workers are mostly engaged in the odd-job economy with their professional skills, this makes human capital at the odd-job level proprietary, but the positions and job content of their side jobs are somewhat random, and the impact of such jobs on the value of their human capital is also random, but it is certain that this randomness has a positive impact. Thus, in terms of the organisation's stochastic rewards for human capital, the value of an individual's human 
capital increases as they participate in the odd-job economy, but with a degree of stochasticity depending on the task and position.

\subsection{Promote the continuous improvement of organisational performance.}

The development of the gig economy is also beneficial to enterprises or organisations. Because the most prominent feature of the gig economy relies on the Internet platform, which is not affected by physical space or even limited by time, it can significantly increase the capacity of the talent pool and give enterprises or organisations more chances for preference. At the same time, the various situations of talents are profiled in the form of big data, which will significantly improve the efficiency of screening and comparing relevant skills. Therefore, the improvement of human resource development efficiency directly affects the continuous improvement of the performance of the enterprise or organisation. In this scenario, the increase in the value of the firm's human capital is then calculated as:

$$
V=\sum_{t=1}^{n} \frac{F C F F_{t}}{(1+W A C C)^{t}}
$$

Where FCFF is the Free Cash Flow of Firm (FCFF) in period $t$ and WACC is the Weighted Average Cost of Capital (WACC) of the firm.

Improved organisational performance is manifested in increased organisational value, that is, the value of the firm itself as a special commodity reflects the degree of market recognition of the firm's product or service offering and expectations of the firm's long-term growth and value-added potential. Therefore, as the value of human capital increases, it also has a positive driving effect at the capital level in terms of organisational value.

\subsection{Save investment in human resource development.}

When companies select odd jobs, they are more concerned with "Immediate workability," that is, they do not need training and development, and they are directly employed to create benefits immediately. Gig workers neither enter the company's core job level nor need to be exposed to its core information content. Such two-way consideration and choice will save time and effort, especially for the organisation; it can save much money for investment in human resource development. Human capital has greater scope to add value than hard capital such as physical and monetary capital. This is because human capital, as "living capital", is innovative and creative, and has the ability to allocate resources effectively and adjust the development strategy of the company to market resilience. The value of human capital refers to all the costs necessary to maintain the reproduction of human capital. Investment in human capital has a higher contribution to GDP growth.

\subsection{The cost of controllable human resources is low.}

Since Gig works have the apparent characteristics of "immediate labour and immediate benefits," the enterprise organisation only recruits odd workers according to their own needs and can leave after meeting the requirements or completing the tasks. Thus, in selecting, educating, and retaining people, there is almost no need for high costs; corporate organisations can also reasonably avoid the risk of brain drain. Furthermore, the combination of "Internet + Gig Economy" gives new momentum to economic development. Therefore, although the human resource cost in the gig economy field requires a quantitative survey of supply-demand, it is also a great liberation and saving for the organisation. The gig economy creates value for workers, enterprises and society. The value creation of HRM needs to be guided and presented with the help of data analysis tools and instruments, seeking the value of HR data analysis (Figure 2) to enhance the value and competitive advantage of the HR function.

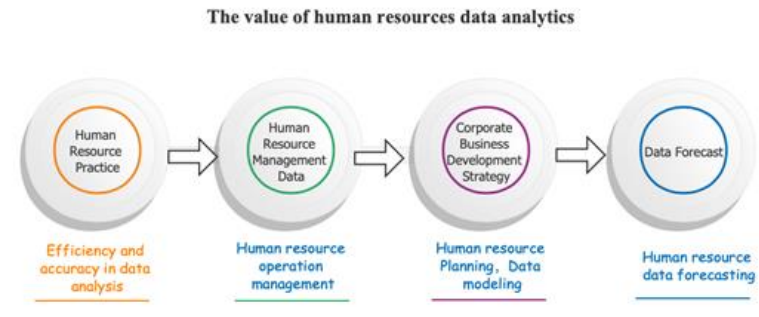

Figure 2 The value of human resources date analytics

\section{STRATEGIC DIFFICULTIES AND RISK CHALLENGES OF HUMAN RESOURCE DEVELOPMENT UNDER THE DEVELOPMENT OF THE GIG ECONOMY}

\subsection{There is a high frequency of gig labour force, and there are potential risks to the work intensity under the employment relationship}

For large-scale enterprise organisations, stable human resource planning is the critical basis for implementing corporate organisational strategies. Employees in the gig economy often end their careers with projects or tasks simultaneously, and employees sometimes have uncertainty. For the gig economy to run 
back and forth, It is necessary to formulate a new human resource plan, which naturally increases this project's time and energy cost. Gig employment is almost a "lifestyle" of most labour globally, and it is changing the "ecosystem" of human resources. The core reason why companies are unwilling to hire long-term workers is that labour costs are too high. From corporate management, the resignation of corporate employees will bring many hidden charges, such as recruitment costs, training costs, management costs, risk costs, Etc. After the epidemic, the cost of recruitment and training has increased. In addition, while growing hidden fees, labour intensity is often more significant than that under long-term employment relationships, which may bring potential risks.

\subsection{Recruitment considerations are too narrow, and human resource allocation judgments are easily unbalanced}

When selecting platforms and selecting employees, enterprise organisations rely primarily on character portraits constructed by big data. The detailed data is used in text or quantitative form to provide an objective and detailed description of the employees' past work experience, achievements, advantages, and disadvantages. Thus, it will make "the good ones are better," and it is also "the weak ones are weaker." At the same time, since most of the gig economy adopts the "project system," the focus of recruiters will only focus on the needs of the project to recruit, and the focus is too narrow and one-sided. Therefore, this seems to be a selection method for the gig economy, but it replaces the corporate organisation to rationally select workers. Besides, it will aggravate the uneven distribution of the labour market, and the allocation of human resources is not reasonable.

In contrast, the barriers to entry for gig workers are relatively low, and it is prone to the phenomenon that the work abilities of the practitioners do not match the description, and the work abilities do not check the requirements of the enterprise organisation. In recruiting part-time workers, the human resources of enterprise organisations are often judged based on the self-introduction and ability display of part-time workers, sometimes showing that their ability is limited and unable to meet the requirements of the enterprise. At the same time, some enterprise organisations mistakenly believe that odd jobs can save enterprise employment costs and require the human resources department to recruit many odd jobs. In general, the employment costs of enterprises have become higher.

\subsection{Insufficient coordination of human resources in border areas can easily lead to deviations in psychological security identity}

The gig economy is also a kind of "shared employees" to some extent. Although the scale of this employment model may continue to grow in the Internet economy, it is not easy to become mainstream. Food delivery platforms generally have two employment models: crowdsourcing vs franchise (agent) employment ${ }^{[7]}$. The crowdsourcing model is the commonly understood work model under the sharing economy, similar to the personal contracting model of online car-hailing express drivers. On the other hand, franchisees hire takeaway riders themselves and form labour relations with them. In principle, they must sign contracts and pay social security. Then these employees work full-time on the platform to take orders. Compared with the two, the advantages of the franchise model are self-evident. In the crowdsourcing model, the above mechanisms may be completely missing. When more supportive management is included in the enterprise organisation, it will give employees more explicit job expectations. However, employees with low psychological security have poor expectations of the future. Employee behaviour will increase stress, lose health, reduce work performance, and bring more turnover. Uncertainties such as unfixed work, unstable income, and inability to enjoy the insurance benefits provided by employers completely replace the traditional employment relationship model and eliminate organisational boundaries. Many shared employees lack a sense of psychological security.

\subsection{Inherent vacancies in job skill training, low level of employment in the highly skilled odd job market}

Because employees in the gig economy are not like regular employees, they need to undergo postemployment skills training, the influence of corporate organisational culture, or the adaptation of job transfer. However, some jobs do not require part-time workers to enter the company group or organisation group, making it challenging to improve their perception of the corporate organisational culture. They cannot accurately understand the vision and mission of the corporate organisation $^{[8]}$. Naturally, they cannot communicate with corporate organisations and social organisations on the upward trend of values. Resonate. The result will be low loyalty, a weak sense of responsibility, and a high turnover rate of gig workers. It also exacerbates the overall planning and recruitment costs to a certain extent. At present, there are relatively few people engaged in skill-sharing odd jobs, and it takes more time and energy. At present, a small number of people in the market have skills-sharing needs. In addition to specific education and training online courses, this also 
leads to the current supply and demand of skills-sharing odd jobs in the market. All are at a low level. However, the company organises human resources to recruit irregular workers, mainly through online channels and lacks sufficient understanding of the ability of odd jobs, and it is straightforward to produce jobs that are completed by odd workers and fail to meet the standards.

\subsection{The boundary of performance is easy to cause disputes, and labour relations are sometimes complex to effectively protect}

When corporate organisations recruit part-time workers, the two parties usually use online channels to communicate and communicate the content of the work. They lack a proper understanding of the ability and quality of part-time workers, and what is ultimately presented is the result of labour ${ }^{[9]}$. For example, the completion standards of creative work such as text creation and picture design are difficult to define, and labour disputes are prone to occur. Not only do companies face the loss of time and material costs, but part-time workers may also encounter corporate fraud. In addition, if a company hires odd workers to provide services to a third-party company when the third-party company is unsatisfied with the results and demands compensation, it is difficult to define whether the liability for payment belongs to the odd worker or the enterprise that hires the odd worker. The settlement of such disputes is undoubtedly human. The work of resource management puts forward higher requirements. If the gig work relationship is determined to be a non-labour relationship, then gig workers cannot enjoy the stable income and social security under the law, leading to labour lawsuits and disputes. On the one hand, corporate human resources have not signed formal, long-term employment contracts with gig workers, and gig workers cannot enjoy the protection of traditional employees in the corporate organisation. On the other hand, it is difficult to intervene in the recruitment of odd jobs by enterprise organisations, and enterprise organisations cannot provide complete labour rights protection for irregular workers.

\section{THE SELECTION ORIENTATION OF HUMAN RESOURCE DEVELOPMENT AND OPTIMISATION PATH IN THE DEVELOPMENT OF THE GIG ECONOMY}

\subsection{Coordinating the fine occupational division and planning and optimising the labour innovation model of part-time employment}

Human resource portraits under big data will make detailed data portraits of labourers. Under the assumption of "a rational economic man", employers will prioritise choosing outstanding labourers, which tends to intensify the "Matthew effect" over time. In this regard, in addition to applying big data to portray "labour portraits", employers should use big data and artificial intelligence technology to classify and subdivide labour content, instead of simply posting JD (Job Description) on the website, focusing on the scope description of the work content. It is because a closer look at the nature of employment, in essence, is not the company hiring someone but the technology that the person has. At present, digital technology represented by artificial intelligence is advancing rapidly. The labour innovation model of gig employment is mainly enhanced and improved from three aspects: free choice and independent management of labourers, continuous optimisation of enterprise human resource management, and strengthened supervision by the government. First of all, at the corporate system level, the focus is on the optimisation of processes and systems, establishing and improving related systems for gig economy employment, formulating specific procedures and rules for gig economy employment, and standardising employee classification and management. Secondly, at the level of the government system, the focus is on legislation and policy regulations, strengthening the legislation and policy regulations for the gig economy, and ensuring that workers in the gig economy have a clear legal basis in terms of taxation, salary, social security, and their rights and responsibilities. Thirdly, at the level of the social system, the focus is on the coordination of labour-management contradictions and the division of interests, encourage the establishment of associations and groups related to the gig economy, fundamentally eliminate social discrimination against gig labour, and effectively guide the scientific allocation of human resources through incentives.

\subsection{Improve the traditional recruitment network docking model, optimise and promote the solution of intelligent decision-making in the industry}

Use transaction model products and new technical systems to solve problems. Currently, there are three solutions to choose from: One is the digitisation of the employment process. Record employees with accurate data matching instead of interviews, use data in the employment process to measure the efficiency and quality of a person's work and achieve proper pricing of talents. The second is the integrity of user files. It is necessary to establish user integrity files, combined with an intelligent decision-making model for order matching so that honest people can accept high-priced orders, and dishonest people can accept low-priced orders or even fail to receive orders. The third is data accumulation and analysis. Based on the data accumulation of the previous two processes, multiple companies on the part-time job platform can share an 
employee, accurately match the company's needs and employees, effectively allocate human resources, and reduce labour costs. In the end, part-time jobs hope to build an honest, character-understanding and intelligent employment transaction channel based on new technologies, new systems, and new models and provide employees and employers with value-added services that are quickly and accurately matched. In a sense, the new model that combines the power of blockchain and AI with odd jobs is a more advanced model than the traditional part-time model. In the future, the gig job market will genuinely be more competitive or rely on data, Technology System. The core is to run faster than anyone, whose product and business model can win users' trust and whose market is ultimate. The more advanced artificial intelligence technology is, the more the gig economy can change people's lifestyles. Build a transaction channel and transaction system in the employment field, return transactions to integrity, and make transactions more intelligent and straightforward. Under the epidemic situation, companies are also working hard to adjust their employment patterns and reduce labour costs. To stabilise the employment of employees and expand business development simultaneously, some companies have launched fancy human resource management models. The employment modes such as "shared employees" and "cross-border employees" are the most eye-catching. In the future, the outbreak of the gig economy is indeed the general trend. The development of artificial intelligence technology will give wings to the development of the gig economy, and it will surely be the ultimate choice for the reform of human resource management in the new era.

\subsection{Improve the automatic evaluation mechanism of performance appraisal to promote the orderly development of employees' internal and external careers}

Generally speaking, to attract and retain talents, corporate organisations often provide bonuses and benefits as necessary incentives. Gig jobs are the external human resources of the enterprise, and they often lack loyalty and sense of belonging to the organisation and quickly lose their sense of responsibility. To stimulate the enthusiasm of odd jobs, setting performance rewards based on the performance appraisal system can ensure the effective achievement of the goals. According to the quality and efficiency of the work done by odd jobs, according to the balance of the performance appraisal and scoring mechanism, partial rewards are given based on the agreed salary. However, for the odd jobs of creative work and knowledge work, the assessment based on bonuses and benefits is not attractive. The main reason is that the focus of talents is not to "make a living", but more to value "development of". Appropriate "delegation of power" allows practitioners to increase decision-making power in projects and work appropriately, and at the same time assume corresponding social responsibilities and open opportunities for integration into groups at appropriate times. At the same time, use big data to improve the construction of learning organisations, create a learning management platform based on employee socialisation and knowledge management, and promote the career development of odd workers at work:

(1) Set up and improve the salary incentive mechanism. Part-time workers often have short working hours, and corporate human resource management should set up a salary incentive system to inspire parttime workers to improve the quality of their work.

(2) Strengthen the awareness of self-protection. Learn new digital technologies, negotiate collectively with platforms or employers, improve working conditions and the environment, and effectively protect their legitimate rights and interests.

(3) Create a quantitative system for assessment and scoring.When recruiting part-time workers, corporate human resources should score part-time labour ability and level. The scoring content mainly includes work attitude, workability, the familiarity of job skills and other related content. Once it is necessary to hire part-time workers again, it is convenient to prioritise the highly evaluated odd workers.

\subsection{Confirm the labour relationship with the enterprise organisation and improve the laws and regulations to protect the legitimate rights and interests}

Protecting gig workers' legitimate rights and interests is a significant theme under the gig economy model. Especially for low-skilled odd workers, longterm protection of labour rights is even more necessary when income and work schedules are unstable. For enterprise organisations, gig workers' legitimate rights and interests are protected, which will relatively reduce labour disputes, make it easier to maintain a long-term cooperative relationship between the two parties, and improve work efficiency ${ }^{[10]}$. Therefore, at the legal level, it is necessary to break through our country's legal system of "all" or "nothing" for labour relations and reidentify the labour relationship between gig workers and corporate organisations. At the social security system level, it is necessary to break through the original security mechanism and set up a separate social security subsystem for the gig workers to provide specific social security for the gig workers in need. The protection and supervision of gig workers' legitimate rights and interests is the most severe challenge facing corporate human resource management: 
(1) Improve the legislation to protect the legitimate rights and interests of gig workers. Relevant legal provisions should be added to ensure that labour's legal rights and interests are guaranteed when the gig is in employment.

(2) Strengthen the responsibilities of the gig recruitment platform. Companies recruit part-time workers often need to use various Internet recruitment websites to show that the recruiting company pays relevant insurance for part-time workers and implements pre-job training guarantees for part-time workers.

(3) Explore "online social security". A new "online social security" model is built for the gig workers to ensure that gig workers protect their legitimate rights and interests.

\subsection{Establish a new development and innovation management mechanism to ensure the effective use of human resources in the gig economy}

(1) We are exploring the establishment of a credibility archive for odd jobs. Establishing an assessment and scoring system can raise the barriers to entry for irregular workers and ensure that workers are prepared for the company's job capability requirements, while the construction of odd job integrity files can restrict the attitude of quirky workers. The human resource management department of the enterprise should build a credibility file for odd jobs and mark the work attitude and abilities of different odd jobs in detail. By establishing a credibility file for odd jobs, formating a transparent mechanism to improve the matching between the company and odd jobs can be effective.

(2) Helping promote institutionalisation at the policy level. On the one hand, it is the guarantee of the legal operation of the enterprise, and on the other hand, it is the protection of the rights and interests of the workers. The emergence of the digital economy, industrial structure adjustment, and population ageing have boosted flexible employment. In terms of choice, one is to ensure social security benefits for the socialised job. The key is to propose improving employment and social security systems that adapt to the characteristics of the new employment patterns. The second is to establish supplementary insurance of a mutual assistance nature. Although social security needs to consider increasing the level of participation in social security for all people, especially for low-income groups, it is necessary to establish supplementary insurance of a mutual assistance nature for workers.

(3) They are improving the rule of law at the level of social satisfaction. On the one hand, the government must further enhance existing laws and regulations to achieve full coverage of the "gig economy" model. Strengthen law enforcement against enterprises and increase the cost of violations of enterprises. Improve the internal management system through the platform enterprises themselves and accelerate the innovation of the management system. On the other hand, for the gig economy, through the combination of blockchain transactions and smart contracts, relying on platform companies, workers and the government to play a synergistic role, develop a new model of gig economy governance, realise joint participation, shared power, and share the gig economy under the unique ecology of sustainable development of human resources.

\section{CONCLUSION}

Based on the above research and analysis in this article, the gig economy can be used as the beginning of the "post-new crown epidemic" era, restarting the global economy and liberating the labour force because it has the flexibility, flexibility, and tension that other economic models do not have. Moreover, it is sustainable for both labour and management space for development. At the same time, with the in-depth application of a new generation of digital technologies represented by the Internet, cloud computing, big data, artificial intelligence, Internet of Things, and blockchain, continues to drive the digital transformation of human resources in the gig economy, the extension of corporate organisational boundaries, the innovation of employment models, as well as the in-depth development and utilisation of human capital have laid the foundation for the development of the spatial dimension of the gig economy. The gig economy is a new form of distribution of human resources. Highlighting is also a challenge for HR. The focus is on the era of open innovation and gig economy, which improves enterprise organisations' human resource management level. In general, the gig economy consists of three parts: gig workers, platforms, and service recipients. Employment relationship--transform from contractual relationship to cooperative relationship; transaction content--change from physical transaction to knowledge transaction; business model--from factordriven system to innovation-driven ecological transformation. From the perspective of three dimensions of individuals, companies, and governments, there will be three major trends in the future: the skills of odd workers, the platform management of employment enterprises, and the systematisation of government and social governance. One of the background factors for the growth of the casual labour economy in Europe and the US today is the growth of online intermediaries providing online platforms. The diversity of microeconomic and labour relations issues based on labour transactions and the 
protection of human rights in the zero-work economy is mainly reflected in the mode of employment, working hours, location, environment, remuneration and management, which play a role in the corporate value, social value and worker value in different areas. And factors such as financial performance, management skills, work ethic, team spirit and innovation determine the contribution of a company's human capital to the value added by the company. The human resource demand sharing platform not only has obvious advantages in the epidemic response process but also needs to provide policy support and traction guarantee in model development and system optimisation to drive the effective allocation of human resources in the gig economy and realise the sustainable development of human resources and maximise the efficiency.

\section{REFERENCES}

[1] Vallas, S., \& Schor, J. B. (2020). What do platforms do? understanding the gig economy. Annual Review of Sociology, 46(1).

[2] Mujtaba, A. . (2018). Entrepreneurship and ethics in the sharing economy: a critical perspective. Journal of Business Ethics, 1-15.

[3] Connelly, C. E., Fieseler, C., Erne, M. , Giessner, S. R. , \& Wong, S. I. . (2020). Working in the digitized economy: hrm theory \& practice. Human Resource Management Review, 31(1), 100762 .

[4] Beardwell, I. (1996). Contemporary developments in human resource management.

[5] Sutherland, W., \& Jarrahi, M. H. (2018). The sharing economy and digital platforms: a review and research agenda. International Journal of Information Management, 43(DEC.), 328-341.

[6] Zheng, Q., \& Yang, W. (2019). Different research perspectives on gig economy_ - a review based on western classical literature. Human Resources Development of China.

[7] Meijerink, J., \& Keegan, A. E. (2019). Conceptualizing human resource management in the gig economy: toward a platform ecosystem perspective. Journal of Managerial Psychology, 34(4).

[8] Kost, D., Fieseler, C., \& Wong, S. I. (2020). Boundaryless careers in the gig economy: an oxymoron?. Human Resource Management Journal, 30(1).

[9] Schroeder, A. N., Bricka, T. M., \& Whitaker, J. H. (2019). Work design in a digitized gig economy. Human Resource Management Review. 